\title{
Yield and Water Use Efficiency of cucumber (Cucumis sativus L.) conducted under subsurface drip irrigation system in a Mediterranean Climate
}

\author{
Boutheina Douh ${ }^{1}$, Amel Mguidiche ${ }^{1}$, Sami Bhouri Khila ${ }^{1}$, Mohsen Mansour ${ }^{2}$, \\ Harrabi Rania ${ }^{1}$, Abdelhamid Boujelben ${ }^{1}$ \\ ${ }^{1}$ Department of Genius of Horticultural Systems and Environment, High Institute of Agronomy, BP 47, Chott \\ Meriem 4042 ,Sousse, Tunisia \\ ${ }^{2}$ Regional Research Center in Horticulture and Organic Farming, BP 57, 4042, Chott Mariem, Sousse, Tunisia
}

\begin{abstract}
The aim of this paper was to evaluate the effects of surface and subsurface drip irrigation buried at 0,15 and $30 \mathrm{~cm}$ depths respectively (T0, T1 and T2) on water's dynamic in soil and irrigation water use efficiency to produce cucumber (Cucumis sativus L.) in Mediterranean climate. Field study was conducted at the Higher Institute of Agronomy of Chott Meriem, Tunisia from April to June 2011. The results showed that soil water's stock under T1 was more important and uniform compared to TO and T2. In contrast, irrigation water use efficiency was higher in T2. Indeed, it increased about 20 and $13 \%$ respectively when compared to $T 1$ and TO. The results of the present study showed that SDI allows uniform soil moisture, minimize the evaporative loss and delivery water directly to the plant root zone and consequently increases use efficiency.

Keywords: subsurface drip irrigation, water use efficiency, Cucumis sativus L., soil water's stock, root length density, yield.
\end{abstract}

\section{Introduction}

As the population grows and urban water use increases, irrigated agriculture is being called on to produce more food using less water, and to do so without degrading soil and water resources [1]. The concept of water saving was further elaborated during the nineteenth century. People involved with irrigation were dissatisfied with the wasteful surface irrigation technologies. In order to reduce the costs of the drip system, perforated thin-wall tapes were introduced. Perforated pipes for subsurface irrigation were used experimentally in Germany in 1920 and in the USSR in 1923. In 1926, Mr. Nelson of Tekoa, Washington, had registered a patent for a subsurface irrigation system. Another subsurface irrigation system was examined in 1934 at the New Jersey and Indiana Agricultural Experiment Stations. After WWII, micro-tubes were used for greenhouse irrigation in England and France. In 1954, Mr. Richard Chapin developed in the USA, drippers for irrigation of potted plants in greenhouse. Mr. Hansen, of Denmark, developed a small plastic tube for the irrigation of potted plants in greenhouses [2]. [3] studied the effect of different depths of subsurface drip irrigation on maize in Chott Meriem-Tunisia. Local information on the response of cucumber growth, yield and other crop-water dynamics with SDI is very limited. The agronomic response of the crop to irrigation with SDI is needed to be able to evaluate the economic and technical feasibility of using SDI under local conditions and provide scientifically based practical information to the users on best management practices for SDI-irrigated corn. The objective of this study was to evaluate how different irrigation depths applied with SDI affected the redistribution of water's stock in soil, agronomics' parameters, yield and water use efficiency in the semiarid climate of Tunisia. The results will also be discussed in the context of other similar work at other locations. The Research supplements a larger body of knowledge. In some cases, existing information about SDI use in other regions and with other crops has been transferable. In other cases, it has not. As in many parts of the world, the interaction of climate, soils, and crop production presents unique combinations that require local research to fine-tune the production systems.

\subsection{Experimental site}

\section{Materials And Methods}

This study was carried out at the Higher Agronomic Institute of Chott Mariem-Sousse. (Longitude $10^{\circ} 38^{\prime} \mathrm{E}$, Latitude $35^{\circ} 55^{\prime} \mathrm{N}$, altitude $15 \mathrm{~m}$ ) from April to June 2011 in order to test the response of cucumber (Cucumis sativus L.) to subsurface drip irrigation with different treatment of burial depth 0,15 and $30 \mathrm{~cm}$ respectively $\mathrm{T} 0, \mathrm{~T} 1$ and $\mathrm{T} 2$. The climate is typically Mediterranean with hot summers and cold winters. According to long term weather data (1973-2006), maximum monthly temperatures range between 16 and $31^{\circ} \mathrm{C}$ and minimum monthly temperature vary from 7 to $21^{\circ} \mathrm{C}$. Mean relative humidity vary from 69 to $71 \%$. Monthly 
rainfall ranges between 2 and $58 \mathrm{~mm}$. Climatic data were recorded from a weather station located about $300 \mathrm{~m}$ far from the experimental area. (fig. 1).

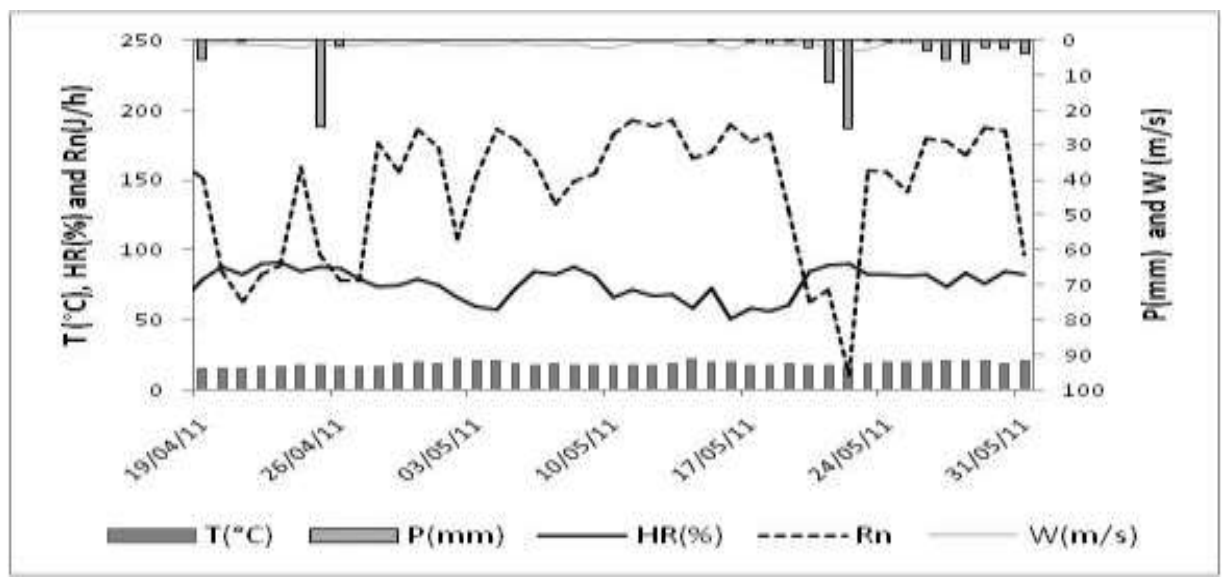

Figure 1. Daily meteorological data in the study area

The soil is sandy loam with average basic infiltration rate of $14 \mathrm{~mm} \mathrm{~h}^{-1}$. The field was precision graded to approximately $1 \mathrm{~mm} \mathrm{~m}^{-1}$ slope. Table 1 showed the measured soil's hydraulic parameters such as residual and saturated soil water content, bulk density, porosity for each layer. Cucumber was seeded the $1^{\text {st }}$ of April with row spacing of $80 \mathrm{~cm}$ and in-row spacing of $40 \mathrm{~cm}$ and the whole planting area is $212 \mathrm{~m}^{2}(22 \mathrm{~m} \times 9.6 \mathrm{~m})$.

Table 1. Measured soil's hydraulic parameters.

\begin{tabular}{lllll}
\hline Layer & & $0-20 \mathrm{~cm}$ & $20-60 \mathrm{~cm}$ & $60-100 \mathrm{~cm}$ \\
\hline Soil class & & Sandy loam & Sandy loam & Sandy loam \\
\hline \multirow{2}{*}{ Texture analysis } & \% sand & 61 & 68 & 52 \\
& \% clay & 31 & 27 & 43 \\
Water content & $\theta_{\mathrm{r}}(\%)$ & 8 & 5 & 5 \\
Hydraulic conductivity & $\theta_{\mathrm{s}}(\%)$ & 0.0640 & 0.0589 & 0.0600 \\
Bulk density & $\mathrm{Kd}(\mathrm{cm} / \mathrm{h})$ & 0.3714 & 0.3711 & 0.3712 \\
Porosity & $\mathrm{Bd}\left(\mathrm{g} / \mathrm{cm}^{3}\right)$ & 1.39 & 1.38 & 0.31 \\
\hline
\end{tabular}

\subsection{Experimental Design and Measurements}

The cucumber crop was irrigated with surface and subsurface drip irrigation during the growing season. Drip tubing (GR type) have a nominal diameter equal to $16 \mathrm{~mm}$, with coextruded emitter spaced $40 \mathrm{~cm}$ apart were installed at depth of 0,15 and $30 \mathrm{~cm}$. Emitter flow rate equal to 41/h was discharged at pressure of $100 \mathrm{KPa}$. The experimental design was presented in figure. 2.

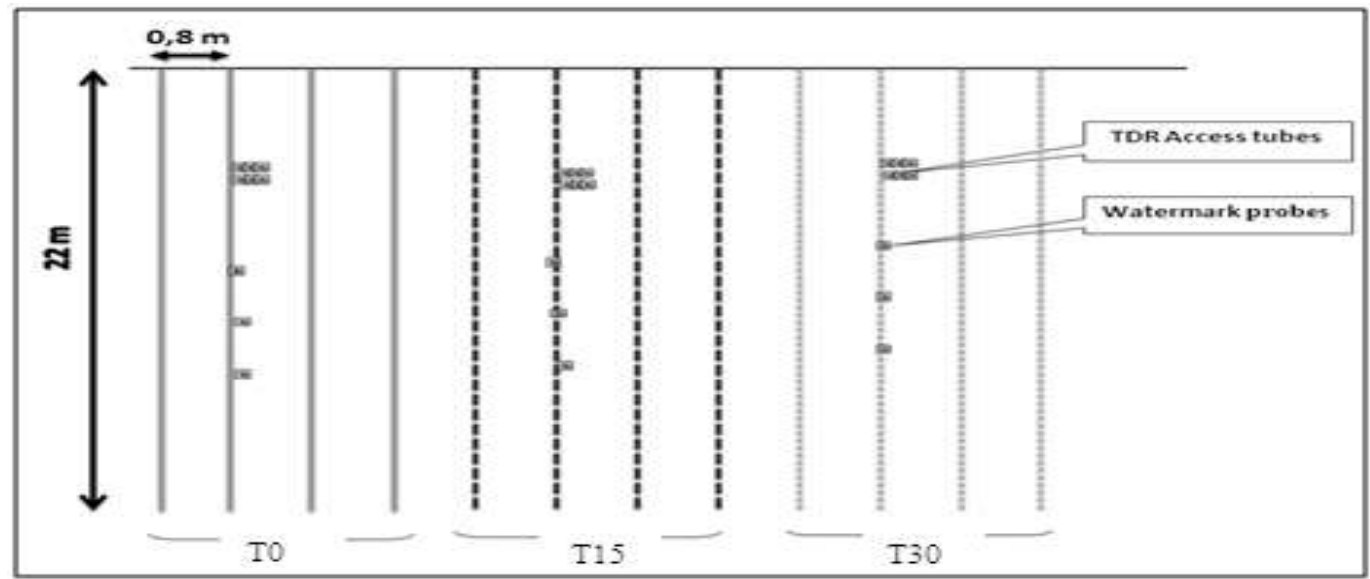

Figure 2. Experimental design of the TDR tubes and Watermark probes

The crop was irrigated by regarding estimated crop water requirements. Irrigation depth for each application was 
half the weekly water requirements. Weather data were obtained from a weather station located adjacent to the experimental area. Time Domain Reflectometry (TDR) technique was used to measure soil volumetric moisture using portable soil moisture monitoring system (TRIME FM). The vertical profile of soil water content in every tube was determined from measurements of volumetric soil water. Soil moisture content was measured daily and the gravimetric sampling technique and steel rings were used to calibrate the TDR display unit. Six measurement tubes were installed for each treatment. The measures were made by a layer of $10 \mathrm{~cm}$ in a tube of $1 \mathrm{~m}$ in length. The measurement tubes were located just under the dripper 0 and $20 \mathrm{~cm}$ apart from the dripper, respectively and in the middle of the in-row spacing at 0,20 and $40 \mathrm{~cm}$, respectively. The data were obtained daily during the irrigation period at approximately 9:00 AM CDT. Water's stock in soil is calculated as integrating the soil volumetric moisture relative to the domain D composed of the elementary soil volumes for a depth of $60 \mathrm{~cm}$.

Since the study of [4], different expressions of water use efficiency, crop water productivity and irrigation water use efficiency have been proposed and discussed [5]- [8]. Water use efficiency (WUE) was identified as one of the key water use indicators derived in the study of sustainable irrigated agriculture indicators [9]. The definition focuses farmer's attention on both water use and production and provides an indication of whether the resource has been used effectively. Water use efficiency (WUE) was calculated as the ratio of Cucumber yield (Y) to total crop water use (WU) as suggested by [10]:

\section{WUE $=$ Y/WU}

Plant yield were determined by weighting above ground of the plants using a $0.01 \mathrm{~g}$ sensitive digital balance The measurements of the leaf area are achieved with the help of an analogical area meter (model LI-3100C Area Meter, LI-COR, Nebraska USA). Then Leaf Area Index (LAI) was calculated.

\subsection{Statistical analysis}

Collected data in this study were analyzed and examined statistically using analysis of variance (ANOVA) from the Statistical Analysis System (SPSS 17.0 for Windows) appropriate for a randomized complete block design. Means were compared by the SNK Test at the 5\% level of significance. The mean values of each treatment are designated by letters $(a, b, c)$ which represent the significance degree of the difference between the means. The letter "a" means the highest average, "b" is the one between "a" and "c". Means represented by two letters in common indicate that the difference is not significant or weakly significant.

\subsection{Water's Stock in Soil}

\section{Results And Discussion}

Water's stock in soil increased after irrigation or rain and decreased between two successive irrigations in absence of rain (Fig.3). This decrease of water stock became more rapidly as the climate became hotter and drier and the crops reached a more advanced vegetative stage. In the same way, figure 3 provided evidence that water's stock was more important in $\mathrm{T} 1$ than in $\mathrm{T} 0$ and $\mathrm{T} 2$. Therefore, the losses of water by evaporation were weaker for the subsurface drip irrigation, but for T2 there were drainage losses. SDI offers many advantages over surface drip irrigation; when it was installed in the proper depth; such as reduced evaporation loss and precise placement and management of water [11]. Whereas, water's stock in soil is greater (10.2\%) in T1 compared to T0 (Fig. 4) and there's a significant difference between the three treatments. [12] studied the water saving and yield increase of sugar beet with subsurface drip irrigation and he found greater water economy of $16.6 \%$ for the SDI in comparison to surface drip.

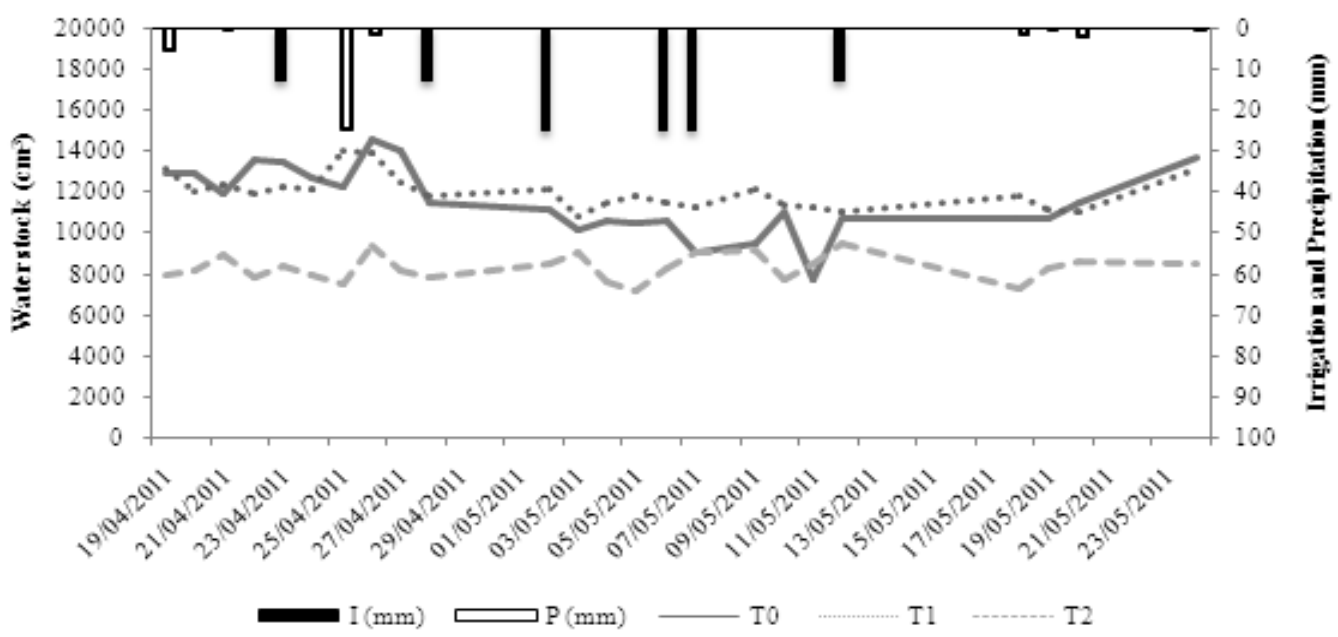

Figure 3. Soil water stock under different depth of subsurface drip irrigation 


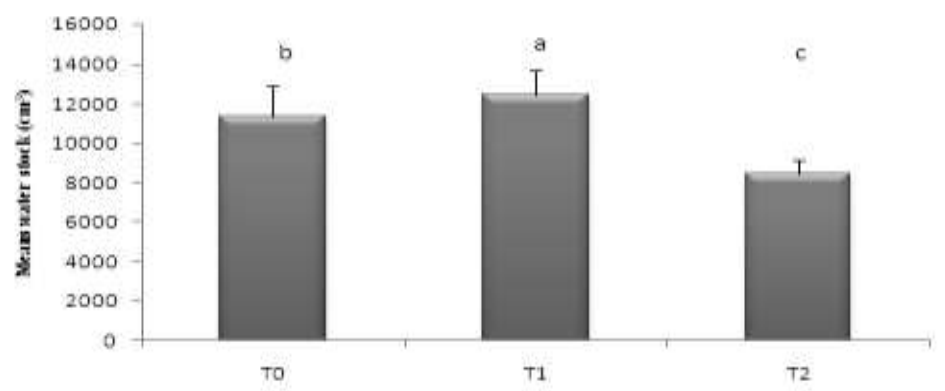

Figure 4. Mean soil water stock for surface and subsurface drip irrigation system

\subsection{Variation of Soil Water Stock}

Figure 5 showed water's stock variation in surface and subsurface drip irrigation system at 15 and 30 $\mathrm{cm}$ depth. The graph can be divided into two parts; the first from 12 to 26 April when the soil water stock's variation was almost similar for all the treatments and the second from 27 April to 30 June when the change became almost stable for the $\mathrm{T} 1$ in contrast to $\mathrm{T} 0$ and $\mathrm{T} 2$ treatments. The amplitude of water stock's variations was more restricted for the T1; therefore the consumption and the losses of water were weaker with this system of irrigation. The relative variation to the water stock's variation was of $13.6 \%$ for $\mathrm{T} 2$ as compared to that of T0. These results are similar to those found by [13], who found an efficiency of $22.9 \%$ in favor of the buried irrigation compared to surface drip irrigation for eggplant. [14] have reported that a successful application of subsurface drip irrigation for 10 years in Kansas, USA reduced the irrigation water use for corn by 35 to $55 \%$ compared with traditional forms of irrigation.

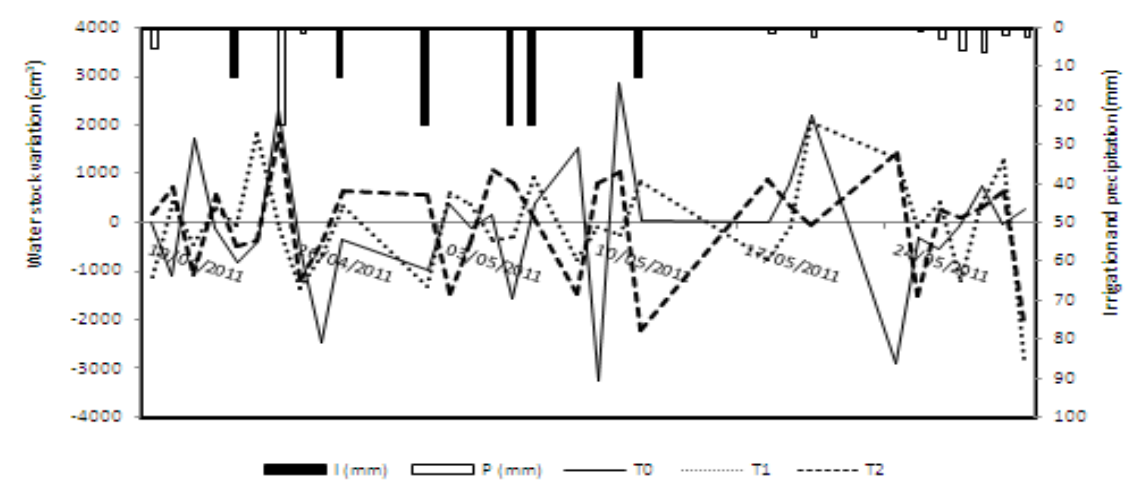

Figure 5. Soil water stock variation under different depth of subsurface drip irrigation

\subsection{Leaf area}

The observation of figure 6 showed a hight significant difference at 5\% level between driplines depths on leaf area. The statistical analysis were classified the treatment effect on leaf area into two groups, the first one was to T2 (a), the second had T0 and T1 (b). The highest results had been recorded in the case of the drip irrigation system buried at $30 \mathrm{~cm}$ with an average of $0.3561 \mathrm{~m}^{2} / \mathrm{plant}$, whereas it didn't exceed 0.2161 and $0.2194 \mathrm{~m}^{2} /$ plant respectively in T0 and T1. That result showed that a driplines deep of $30 \mathrm{~cm}$ allowed a better water availability for the crop. These results are similar to those found by [8] and [13] with other crops such as maize and eggplant.

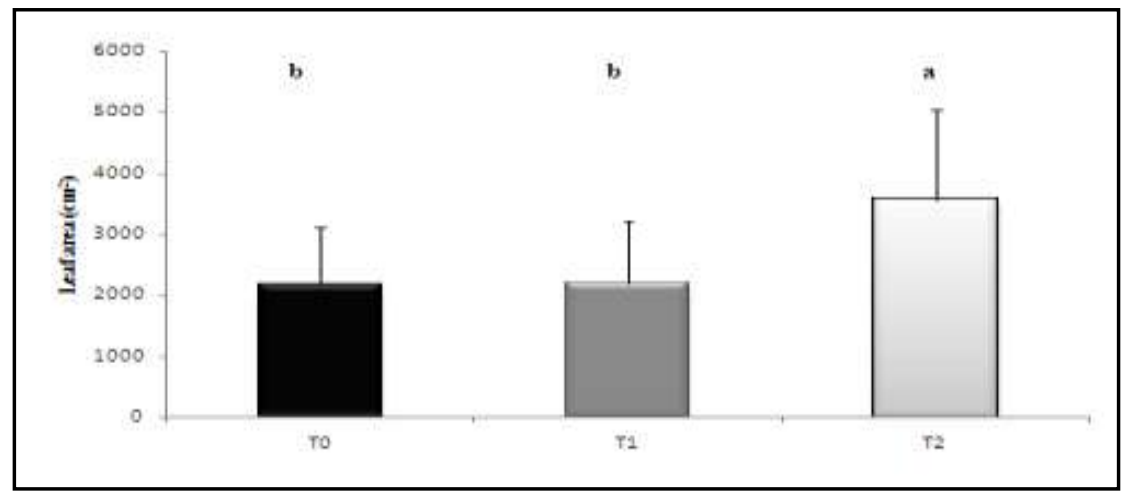

Figure6. Average leaf area for the cucumber crop under surface and subsurface drip irrigation system 


\subsection{Yield}

Figure 7 showed depth effect of subsurface drip irrigation on cucumber yield. There's a highly significant difference between the treatments by performing the SNK test beyond $\alpha=5 \%$. The average yield was about $1.2 .32 ; 2.19$ and $2.71 \mathrm{~kg} \mathrm{~m}^{-2}$ respectively for $\mathrm{T} 0, \mathrm{~T} 1$ and $\mathrm{T} 2$.

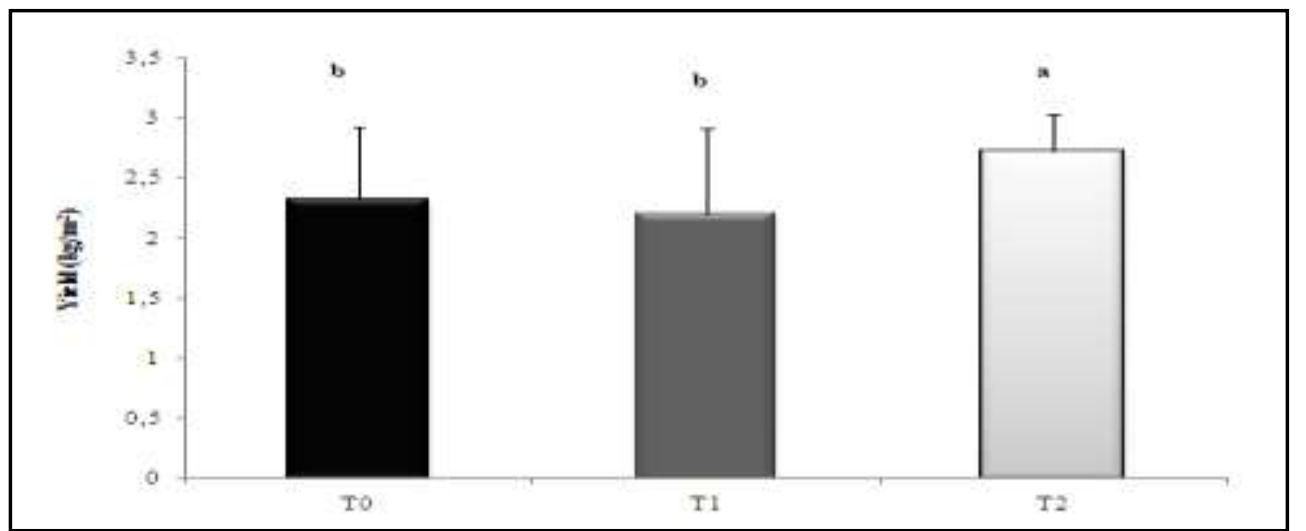

Figure7. Average yield for the cucumber crop under surface and subsurface drip irrigation system [15] showed that water stress significantly affected the yield and yield parameters of early potato production. Water deficiency more than $33 \%$ of the irrigation requirement could not be suggested. Soil water low, transpiration, and extraction of water by roots are generally understood as components of water low in the soilplant-atmosphere continuum [16].

\subsection{Water Use Efficiency (WUE)}

In calculating the WUE, the same quantity of water was been applied to the surface and the subsurface drip irrigation system at 15 and $30 \mathrm{~cm}$. Since there was a significant yield difference between the two irrigated treatments, the treatment with the higher yield had the higher WUE (fig. 8). There was no significant WUE difference between the treatments. But the highest values were recorded in T2 $\left(15 \mathrm{~kg} \mathrm{~m}^{-3}\right)$. In fact, it increased about 20 and $13 \%$ respectively when compared to $\mathrm{T} 1$ and $\mathrm{T} 0$. The yield potential of cucumber was reduced by soil moisture stress and consequently on the yield and IWUE of maize. In addition, subsurface drip irrigation allows uniform delivery of water directly to the plant root zone. This can increase use efficiency over other irrigation methods. The WUE values of this study were upper than some values reported in the literature [17]. These differences could be explained by the fact that this study was conducted in more arid environment. However, these results are consistent with those found by [18] who studied the effect of subsurface drip irrigation system on cucumber cultivation in China, and found a water use efficient in the order of $0.056 \mathrm{t} / \mathrm{ha} / \mathrm{mm}$.

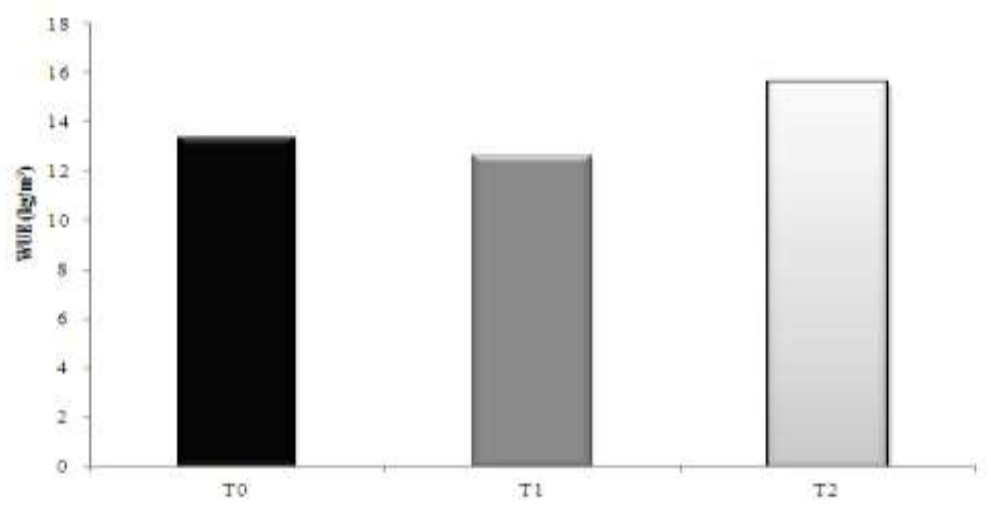

Figure 8. Average water Use Efficiency for the cucumber crop under surface and subsurface drip irrigation system

These consistently large water productivities obtained in this study are further evidence that drip line depht of $30 \mathrm{~cm}$ was probably acceptable on our soil type and climate for cucumber production when the crop is fully irrigated. We verified that WUE is an on indicators of crop water status, demonstrated that soil water status assessed through criteria like soil water content, volume of water supply, humidity, or soil water potential constitute an imperfect parameter to characterize real plant water status, and it leads consequently to variability in WUE. They recommend the use of leaf water potential or pre-dawn leaf water potential in order to identify 
the actual crop water scheduling and to guide water supply. Under these conditions, yield, water use and, in consequence, WUE should present more stable values. [19] added that there is no consistent relationship between plant production and WUE. It may therefore be further concluded that for conditions where high WUE is an advantage because it is a marker for low water use, selection for the preferred plant type can be done by directly selecting for small plant size, small leaf area, or reduced growth duration. These results are confirmed by [20] who put the same hypothesis to explain the amplification of water use efficiency of cucumber and tomato crops relatively to SDI.

\section{Conclusion}

This study indicated that soil water's stock was more important in T1 than in T0 and T2. It registered an improvement of $10.2 \%$ compared to $\mathrm{T} 0$ and there's a significant difference between the three treatments. In addition, water's stock under subsurface drip irrigation at $15 \mathrm{~cm}$ depth was more uniform in comparison to other treatments. Moreover, the highest values of water use efficiency were recorded in T2 $\left(15 \mathrm{~kg} \mathrm{~m}^{-3}\right)$. In fact, it increased about 20 and $13 \%$ respectively when compared to T1 and T0. The highest values of the leaf area had been recorded in the case of the drip irrigation system buried at $30 \mathrm{~cm}$ with an average of $0.3561 \mathrm{~m} / \mathrm{plant}$, whereas it didn't exceed 0.2161 and $0.2194 \mathrm{~m}^{2} /$ plant respectively for $\mathrm{T} 0$ and $\mathrm{T} 1$. The average yield was about. 2.32; 2.19 and $2.71 \mathrm{~kg} \mathrm{~m}^{-2}$ respectively for T0, T1 and T2.There's a highly significant difference between the treatments by performing the SNK test beyond $\alpha=5 \%$.Subsurface drip irrigation allowed uniform soil moisture, minimize the evaporative loss and delivery water directly to the plant root zone which can increases use efficiency. Further observations are needed to determine whether corn production with SDI is feasible in the arid region to develop recommendations for farmers choosing to adopt the method.

\section{References}

[1] T.H. Skaggs, T.J. Trout, J. Simunek, P.J. Shouse, Comparison of HYDRUS -2D simulations of drip irrigation with experimental observations, Journal of Irrigation and Drainage Engineering 130, 2004, 304-310.

[2] S. Moshe, Drip Irrigation (Second Edition, Irrigation Consultant and Former Director, Irrigation and Soil Field Service, 2005).

[3] B. Douh, Etude théorique et expérimentale de l'irrigation goutte à goutte souterraine sur une culture de maïs (zea mays L.), university of sousse, Higher Agronomic Institute of chott Meriem, Tunisia, 2012.

[4] C.T. De Wit, Transpiration and crop yields, Versl. Landbouwk. Onderz. 64.6, Pudoc, Wageningen, $1958,88$.

[5] P.E. Rijtema, G. Endrödi, Calculation of production of potatoes, Neth. J. Agric. Sci. 18, 1970, 26-36.

[6] P.J. Slabbers, V. Sorbello Herrendorf, M. Stapper, Evaluation of simplified water crop yield models, Agric. Water Manage, 1979, 95129

[7] J.T. Ritchie, Efficient water use in crop production: discussion on the generality of relations between biomass production and evapotranspiration, in: H.M. Taylor, W.R. Jordan, T.R. Sinclair (Eds.), Limitations to Efficient Water Use in Crop, 1983, 29-44.

[8] B. Douh, A. Boujelben, Improving water use efficiency for a sustainable productivity of agricultural systems with using subsurface drip irrigation for maize (Zea mays L.), Journal of Agricultural Science and Technology B1 (JAST), 2011, 881-888.

[9] LE, Indicators of sustainable irrigated agriculture, Report No 2720/1, prepared for MAF policy, Lincoln Environmental, a division of Lincoln Ventures Ltd, 1997.

[10] T.A. Howell, Irrigation's role in enhancing water use efficiency, in: R.G. Evans, B.L. Benham, T.P. Trooien (Eds.), Proceedings of the 4th Decennial Natl. Irrig. Symp., ASAE, St. Joseph, MI, 2000, 66-80.

[11] C.R. Camp, Subsurface drip irrigation: a review, Transactions of the American Society of Agricultural Engineers 4, $1998,1353-1367$.

[12] M. Sakellariou, D. Kalfountzos, P. Yyrlas, Water saving and yield increase of sugar beet with subsurface drip irrigation, Global Nest: the Int. J. 4, 2002, 85-91.

[13] B. Douh, A. Boujelben, Study of subsurface drip irrigation on eggplant (European Academic Editions, 2010).

[14] F.R. Lamm, T.P. Trooien, Subsurface drip irrigation for corn productivity: a review of 10 years of research in Kansas, Irrig. Sci. 22, 2003, 195-200.

[15] O. Sermet, C. Mehmet Emin, O. Derya, C. Sergi, Different irrigation methods and water stress effects on potato yield and yield component, Agricultural water management, 2005, 73-86.

[16] P.J. Kramer, J.S. Boyer,). Water relations of plants and soils (Academic Press, San Diego,1995).

[17] T.A. Howell, K.S. Copeland, A.D. Schneider, D.A. Dusek, Sprinkler irrigation management for corn-Southern Great Plains, Transactions of the American Society of Agricultural Engineers 32, 1989, 147-154.

[18] W. Zhenying, L. Zuoxin, L. Zikun, L. Zhang, Subsurface drip irrigation scheduling for cucumber ( Cucumis sativus L.) grown in solar greenhouse based on $20 \mathrm{~cm}$ standard pan evaporation in Northeast China, Scientia Horticulturae - Sci Hort-Amsterdam, 123.(1), 2009, 51-57.

[19] A.G Condon; R.A Richards; G.J Rebetzke and G.D Farquhar, improving intrinsic water-use efficiency and crop yield., Crop Sci., 42, 2002, 122-131.

[20] R.M. Bajracharya, S. Sharma, Influence of drip-irrigation method on performance and yields of cucumber and tomato, Int J. Appl Sci Eng Tech. 1, 2005, 1-7. 